\title{
Adubação orgânica na cultura da batata cultivar Ágata
}

\author{
Organic fertilization in potato culltivar Ágata \\ Fertilización Organica en cultivo de papa Ágata
}

Recebido: 14/05/2021 | Revisado: 20/05/2021 | Aceito: 17/06/2021 | Publicado: 01/07/2021

\author{
Lucas Ferrari Alvarenga \\ ORCID: https://orcid.org/0000-0003-1622-8942 \\ Universidade Federal da Fronteira Sul, Brasil \\ E-mail: lucas.alvarenga@araguaia.com.br \\ Gabriela Gerhardt da Rosa \\ ORCID: https://orcid.org/0000-0002-5023-3414 \\ CEDUP - Professor Jaldyr Bhering Faustino da Silva, Brasil \\ E-mail: birela89@gmail.com \\ Edemar Jose Baranek \\ ORCID: https://orcid.org/0000-0002-6412-8439 \\ Universidade Federal da Fronteira Sul, Brasil \\ E-mail: edemar.baranek@uffs.edu.br \\ Jackson Kawakami \\ ORCID: https://orcid.org/0000-0003-2422-1564 \\ Universidades Estaduais do Centro-Oeste, Brasil \\ E-mail: jkawakami@unicentro.br \\ Cláudia Simone Madruga Lima \\ ORCID: https://orcid.org/0000-0002-1953-1552 \\ Universidade Federal da Fronteira Sul, Brasil \\ E-mail: claudia.lima@uffs.edu.br
}

\begin{abstract}
Resumo
Importante setor da agricultura mundial a bataticultura destaca-se por sua produção apresentar dificuldades e desafios, entre eles está o manejo adequado da fertilização, principalmente do nitrogênio, diante disso com este trabalho, objetivou-se testar fontes e doses de nitrogênio na emergência da batata cultivar Ágata, O trabalho foi realizado a campo na unidade experimental da Universidade Federal da Fronteira Sul, campus Laranjeiras do Sul, no setor de Horticultura. Foram utilizadas quatro fontes de adubação,cama de aviário curtida, cama de aviário peletizada

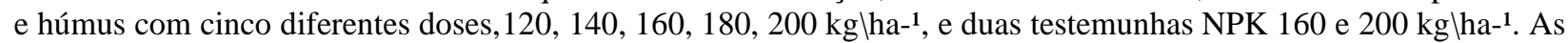
batata semente foram fornecidas pela UNICENTRO, o plantio foi realizado no mês de outubro. As variáveis foram avaliadas 14 dias após plantio, sendo contagem de tubérculos emergidos, e incidência de podridão nos tubérculos. Verificou-se a presença em $100 \%$ dos tubérculos de Pectobacterium sp. O maior percentual de emergência foi obtido com a testemunha, NPK $200 \mathrm{~kg} h \mathrm{ha}^{-1}$, seguido de cama de aviário peletizada $120 \mathrm{~kg} \mathrm{haq}^{-1}$. A utilização de cama de aviário curtida $140 \mathrm{~kg} \backslash$ ha- $^{1}$ proporcionou menor número de batatasemergidas. Conclui-se que o NPK $200 \mathrm{~kg} \backslash \mathrm{N} \backslash \mathrm{ha}-{ }^{1}$ apresentou valores superiores aos demais tratamentos entretanto não é usualmente utilizado pelos bataticultores. A

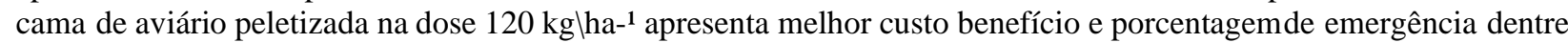
as adubações orgânicas.
\end{abstract}

Palavras-chave: Pectobacterium sp; Fertilizantes; Germinação; Adubos orgânicos; Bataticultura.

\begin{abstract}
An important sector of world agriculture, potato cultivation stands out because itsproduction presents difficulties and challenges, among them is the adequate managementof fertilization, mainly of nitrogen. With this work, the objective was to test sources anddoses of nitrogen in the emergence of potatoes cv Ágata, The work was carried out in thefield at the experimental unit of the Federal University of Fronteira Sul, Laranjeiras do Sul campus, in the Horticulture sector. Three sources of fertilization were used, tanned poultry litter, pelleted poultry litter and humus with five different doses, 120, 140, 160, 180, $200 \mathrm{~kg} h \mathrm{ha}^{-1}$, and two NPK 160 and $200 \mathrm{~kg} h \mathrm{ha}^{-1}$, testemun controls. . Seed potatoes were supplied by UNICENTRO, planting took place in October. The variables evaluated 14 days after sowing were the number of emerged tubers and the incidence of rot in the tubers. The presence of $100 \%$ of the tubers of Pectobacterium sp. The highest percentage of emergence was obtained with the control, NPK $200 \mathrm{~kg} \backslash \mathrm{ha}-{ }^{1}$, followed by pelletized

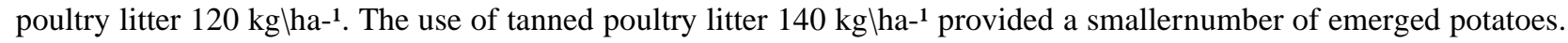
It is concluded that the NPK $200 \mathrm{~kg} \backslash \mathrm{N} \backslash$ ha- ${ }^{1}$ showed highervalues than the other treatments, however it is not usually used by potato growers. The pelleted poultry litter at a dose of $120 \mathrm{~kg} h \mathrm{ha}^{-1}$ has the best cost-benefit ratio and emergence percentage among organic fertilizers.
\end{abstract}

Keywords: Pectobacterium sp; Fertilizers; Germination; Organic fertilizers; Potatoes. 


\begin{abstract}
Resumen
Un sector importante de la agricultura mundial, el cultivo de la papa se destaca porque su producción presenta dificultades y desafíos, entre ellos se encuentra el adecuado manejo de la fertilización, principalmente de nitrógeno, por lo que con este trabajo el objetivo fue probar fuentes y dosis de nitrógeno en el emergencia de la papa, cultivar Ágata, El trabajo se llevó a cabo en el campo en la unidad experimental de la Universidad Federal de Fronteira Sul, campus Laranjeiras do Sul, en el sector de Horticultura. Se utilizaron cuatro fuentes de fertilizantes, cama de ave

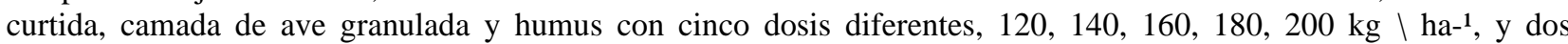
controles NPK 160 y $200 \mathrm{~kg} \backslash$ ha-testemun. UNICENTRO suministró patatas de siembra, la siembra se llevó a cabo en octubre. Las variables se evaluaron 14 días después de la siembra, siendo el número de tubérculos emergidos y la incidencia de pudrición en los tubérculos. La presencia del 100\% de los tubérculos de Pectobacterium sp. El mayor porcentaje de emergencia se obtuvo con el control, NPK $200 \mathrm{~kg} \backslash$ ha-1, seguido de cama de aves granulada $120 \mathrm{~kg} \backslash$ ha-1. El uso de $140 \mathrm{~kg} \backslash$ ha- ${ }^{1}$ de lecho para aves de corral curtido proporcionó una menor cantidad de papas emergidas. Se concluye que el NPK $200 \mathrm{~kg} \backslash \mathrm{N} \backslash$ ha- ${ }^{1}$ mostró valores más altos que los otros tratamientos, sin embargo no suele ser utilizado por los productores de papa. La cama granulada para aves a una dosis de $120 \mathrm{~kg} \backslash$ ha- $^{1}$ tiene la mejor relación costo-beneficio y porcentaje de emergencia entre los fertilizantes orgánicos.
\end{abstract}

Palabras clave: Pectobacterium sp; Fertilizantes; Germinación; Fertilizantes organicos; Bataticultura.

\title{
1. Introdução
}

A batata (Solanum tuberosum L.) é a quarta maior cultura alimentícia do mundo (Sausen, 2020, p. 7484). No Brasil foram produzidos $3.774,1$ t. no ano de 2019. A produção paranaense corresponde a $22 \%$ da produção nacional. Isso coloca o estado como o terceiromaior produtor do país, atrás apenas de Minas Gerais e São Paulo, que respondem por $32 \%$ e $24 \%$ da produção, respectivamente (IBGE, 2020).

Das cultivares de batata mais plantadas no Brasil destaca-se a Ágata que é uma dascultivares com maior aceitação no mercado para comercialização do tubérculo in natura (Cardoso et al. 2017, p.570). De origem holandesa é plantada em cerca de $90 \%$ da área do país. As plantas apresentam características como porte baixo $( \pm 60 \mathrm{~cm})$, ciclo precoce a muito precoce $(90$ a 110 dias), alta produtividade, podendo chegar a mais de $60 \mathrm{t} \mathrm{ha}^{-1}$. Os tubérculos são ovais, casca amarela e predominantemente lisa, polpa de cor amarelo-claroe olhos superficiais (Queiroz, 2011, p. S2131). Apresenta baixo conteúdo de matéria seca(inferior a 17,9\%) (Braun et al., 2010, p.287).

Um fator fundamental na bataticultura é a adubação. A utilização indiscriminada de fertilizantes está presente nas áreas de cultivos de batata e, em consequência desse usoexcessivo, ocorre o aumento do custo de produção, além da redução da qualidade dos tubérculos. Em geral, produtores de batata fazem uma única adubação no plantio ou fazemuma adubação de cobertura com nitrogênio, junto com a operação de amontoa (20 a 30 dias após a brotação). Esse é um dos nutrientes com alto custo tanto energético como financeiro, além de ser o elemento mais exigido pela cultura (Nobile et al. 2012, p.25).

Dentre os adubos orgânicos atualmente disponíveis em escala comercial podemos citar a adubação com cama de aviário, que possui elevados teores de nitrogênio $(\mathrm{N})$, fósforo $(\mathrm{P})$ e potássio $(\mathrm{K})$ (Katayama, 2018, p.171). Além de fornecer nutrientes, promove aumento nos atributos físicos do solo, atuando como condicionador de solo. A aplicação da cama de aviário curtida, apresenta maior concentração de íons hidrogênio (H+), favorecendo a transformação da Amônia (NH3) em Amônio (NH4+) (Mottin et al. 2015, p.159). A cama de aviário pode passar por um beneficiamento, a peletização, e com isso facilitar sua aplicação. Como esse processo se utiliza de temperaturas elevadas, acarreta menor contaminação por patógenos do material (Reis et al. 2018). A cama de aviário tem mineralização e disponibilização de nitrogênio mais rápida que outros estercos, comoo bovino, por exemplo (Peixoto Filho et al., 2013, p.421).

O húmus de minhoca apresenta como principais vantagens no solo o aumento do teor de matéria orgânica e da atividade microbiana; melhoria na estrutura e contribuição para o equilíbrio do pH do solo. E ainda, fornece elementos essenciais como N, P, K, enxofre (S) e micronutrientes (Góes et al. 2011, p.127). Apresenta lenta liberação de nutrientes (Freitas et al., 2012). Para Armond et al. (2016, p.441), o húmus serve como fonte de energia e nutrientes para o desenvolvimento de muitos grupos de organismos, principalmente microrganismos, como resultado de sua decomposição, há 
a liberação contínua de $\mathrm{CO} 2$, $\mathrm{NH} 4+$, íons de $\mathrm{P}, \mathrm{S}$ e micronutrientes.

A emergência da batata inicia com a plena brotação que se caracteriza pela presença de brotos laterais com pelo menos dois milímetros de comprimento. Essa fase corresponde ao período entre o crescimento vigoroso de muitos brotos em diferentes regiões do tubérculo e o momento em que ocorre a ramificação dos brotos. A taxa de crescimento dos brotos é variável e está relacionada com a duração desse estágio. Fatorescomo a temperatura, a umidade, o tamanho do tubérculo e a cultivar interferem na duraçãodo estágio de plena brotação (Bisognin, 2009, p.19).

A plena brotação é o estágio fisiológico que os tubérculos-semente devem ser plantados, o que resultará em uma emergência rápida e uniforme de várias hastesprincipais oriundas de cada tubérculo. Com o crescimento dos brotos ocorre o início da formação das raízes, que é o último estágio da fase de brotação. O crescimento dos brotospromove a formação dos primórdios radiculares na base dos brotos. Tubérculos nesse estágio apresentam um rápido envelhecimento fisiológico, o que levará a senescência deles se não plantados. O plantio dos tubérculos promove a formação das raízes e o rápidocrescimento dos brotos, que emergem do solo e formam as hastes principais, que se ramificam acima ou até mesmo logo abaixo do nível do solo (Bisognin, 2009, p.24).

Adubos orgânicos podem afetar a germinação e a emergência de plantas. De acordo com Silva Junior et al., (2015) os compostos orgânicos presentes nos adubos proporcionam aumento no índice de velocidade de emergência de acordo com a espécie empregada. Entretanto, segundo Duarte et al. (2010, p.1634), conforme a dose esses compostos podem reduzir a velocidade de emergência. E ainda, ocasionar queima parcial ou total de plântulas. A utilização de resíduos orgânicos principalmente na forma de compostos, quecontém altos teores de matéria orgânica, contribui para o maior armazenamento de carbono no solo. Dessa forma, promovem o aumento da capacidade de troca catiônica, uma maior complexação de elementos tóxicos e de micronutrientes (Silva Junior et al., 2015, p.1986).

Diante deste cenário e da importância da adubação na cultura da batata, o objetivoneste trabalho foi verificar a influência de diferentes adubos orgânicos e doses denitrogênio na emergência de batata cultivar Ágata.

\section{Metodologia}

O experimento foi realizado na área experimental de horticultura da UniversidadeFederal da Fronteira Sul (UFFS),

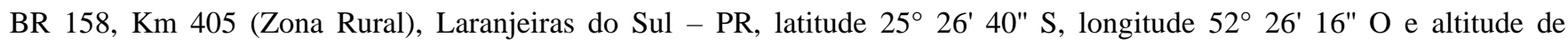
aproximadamente 806 metros. O período de realização foi de setembro a novembro de 2019.

O solo é classificado como Latossolo Vermelho (EMBRAPA, 2006). O clima da região segundo a classificação de Köeppen é do tipo $\mathrm{Cfb}$, subtropical mesotérmico úmidocom verões temperados; as temperaturas médias ficam abaixo de $18^{\circ} \mathrm{C}$ no mês mais frio e abaixo de $22^{\circ} \mathrm{C}$ no mês mais quente (Calviglione et al. 2000). Durante o período de execução do experimento as médias de temperaturas mínimas e máximas ficaram entre 17,4 e $28,06^{\circ} \mathrm{C}$, respectivamente, e as de precipitação acumulada em aproximadamente 452,7mm (Figura 1) (UFFS, 2019). 
Figura 1: Valores médios de precipitação $(\mathrm{mm})$, temperaturas $\left({ }^{\circ} \mathrm{C}\right)$ mínima, média e máxima do ar nos meses de setembro e novembro de 2019, Laranjeiras do Sul-PR. Dadosobtidos na estação climática da UFFS - Laranjeiras do Sul-PR.

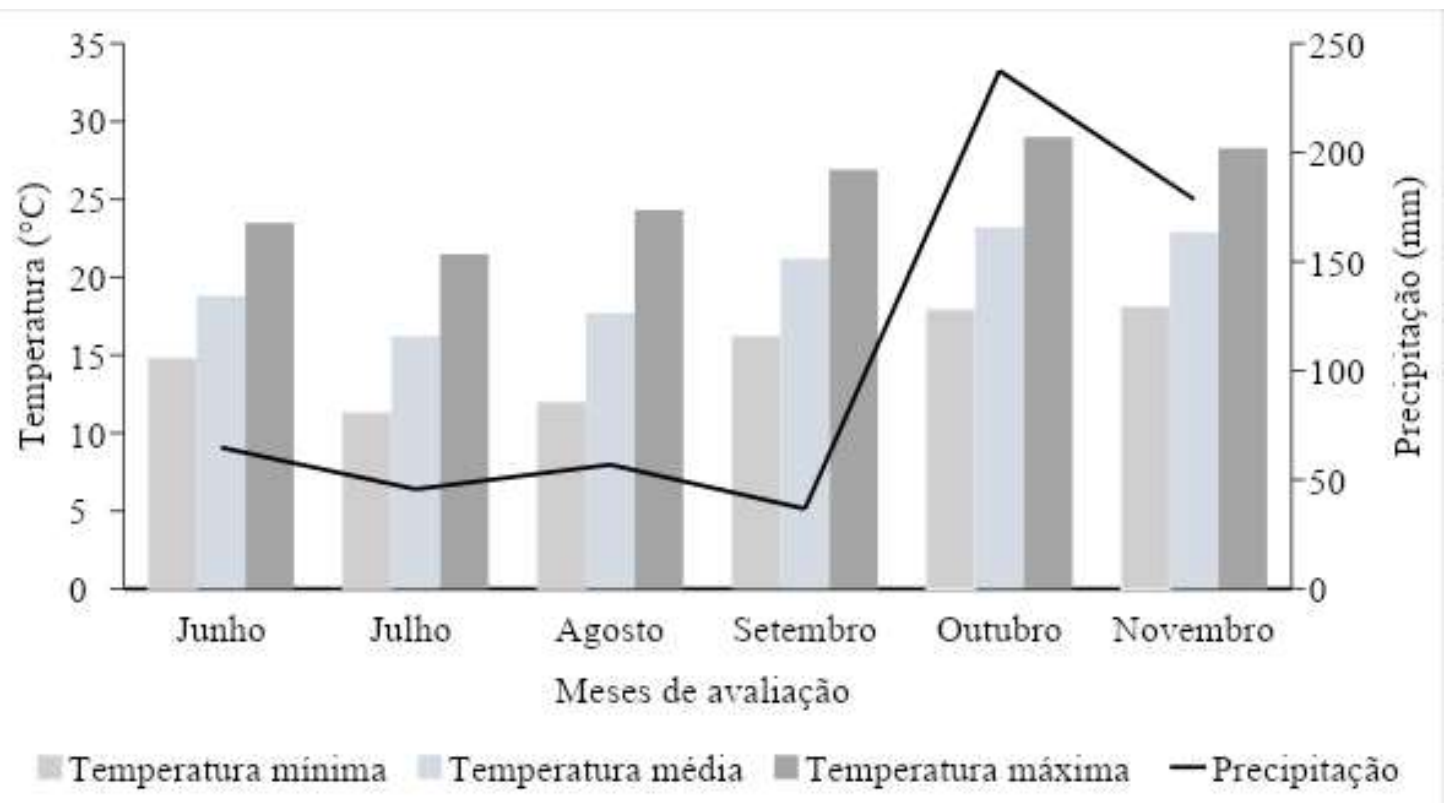

Fonte: Autores.

No local de implantação do experimento realizou-se coleta de solo, sendo realizadas correções de acordo com manual de adubação e calagem. A condução e montagem do experimento foram realizadas de acordo com Girotto et al., (2021, p.4).

O preparo do solo deste experimento foi realizado de forma convencional trinta dias antes da instalação dele. As operações realizadas foram subsolagem, seguida de trêsgradagens e aplicação de fosfato natural reativo e cloreto de potássio $(\mathrm{KCl})$. Posteriormente, mais uma gradagem. Subsequentemente, realizou-se o sulcamento, com distância de 0,8 metros cada, seguido da demarcação dos blocos e parcela.

Os tratamentos consistiram em três fontes de nitrogênio de adubos orgânicos sendo cama de aviario curtida (1-1-1), cama de aviário peletizada (1-0-1) e húmus (1-1-1). E ainda, adubação mineral NPK (4-14-8) como testemunha. As fontes orgânicas foram testadas em cinco doses de nitrogênio: 120, 140, 160, 180 e $200 \mathrm{~kg} \mathrm{~N} \mathrm{ha}{ }^{-1}$. As testemunhas NPK, 160 e 200 $\mathrm{kg} \mathrm{N} \mathrm{ha}^{-1}$, dose padrão recomendada para cultura e dose acima da recomendação, respectivamente. O delineamento experimental foi o em blocos ao acaso com 4 repetições. Cada parcela possuía 3,2 x 2,4, m (7,68 m²), sendo composta por 4 linhas, com 8 plantas cada, espaçadas em $0,8 \mathrm{~m}$ entre linhas e $0,3 \mathrm{~m}$ entre plantas.

Os fertilizantes foram distribuídos e incorporados manualmente no sulco, antes do plantio. Como material propagativo foi utilizado batata-sementes comerciais dacultivar Ágata, cedidas pela Universidade Estadual do Centro- Oeste (UNICENTRO), os tubérculos apresentavam estágio fisiológico plena brotação. As batatas-sementes foram distribuídas no sulco de plantio, onde receberam aplicação de Calda Bordalesa $2 \%$ (a base de sulfato de cobre) seguindo a recomendação para e cultura, após foi realizado o fechamento dos sulcos.

As variáveis avaliadas quatorze dias após semeadura foram: contagem de tubérculos emergidos, e incidência de podridão nos tubérculos conforme descrito por (Passos, 2016, p.55). Para a identificação de patógenos em cada parcela foram coletados quatro tubérculos, devidamente identificados, separados e destinados ao laboratório de Fitopatologia da UFFS. A identificação foi realizada de acordo com metodologia proposta por Alfenas (2016, p.362), todas as amostras foram cultivadas em meio de cultura BDA (batata, dextrose, ágar) e ágar nutriente, utilizando técnica de semeadura em esgotamento. 
Os dados foram submetidos à análise de variância (ANOVA), quandosignificativos foram submetidos à análise de regressão.

\section{Resultados e Discussão}

Para as fontes de adubação cama peletizada e húmus verificou-se um menor percentual de emergência nas doses de

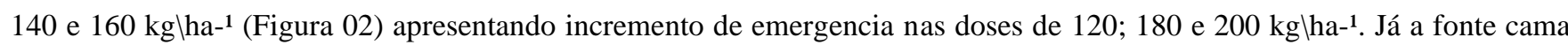
curtida apresentou incremento de emergência apenas na dose de $160 \mathrm{~kg} \backslash \mathrm{ha}{ }^{-1}$.

Quando comparadas a fonte cama peletizada com a testemunha (NPK) constatou-se que ambas as fontes proporcionaram incremento no percentual de emergência nas doses de120, 180 e $200 \mathrm{~kg} \backslash \mathrm{ha} \mathbf{-}^{1}$. Comportamento semelhante foi verificado com a utilização de cama curtida na dose de 160 kgไha-1, assim como, com o uso de húmus a 180 e $200 \mathrm{~kg} \backslash$ ha- ${ }^{1}$.

Os resultados abtidos por Girotto et al., (2021, p.5) coroboram com os dados aqui apresentados, em ambos trabalhos quando utilizada a fonte de nitrogenio cama curtida, obte-ve desenvolvimento favorecido dos tuberculos, bem como, quando do fornecimento das doses mais elevadas de nitrogenio em sistema de adubação organica.

Em relação à comparação feita com a testemunha (NPK) na maior dose $\left(200 \mathrm{~kg} \backslash \mathrm{ha}{ }^{-1}\right)$ nenhuma das fontes e doses de adubo orgânico apresentou percentual de emergência superior.

Figura 2: Porcentagem de emergência de tubérculos de batata cultivar Ágata em funçãoda aplicação de diferentes fontes e doses de adubo nitrogenado. Universidade Federal daFronteira Sul - PR, 2021.

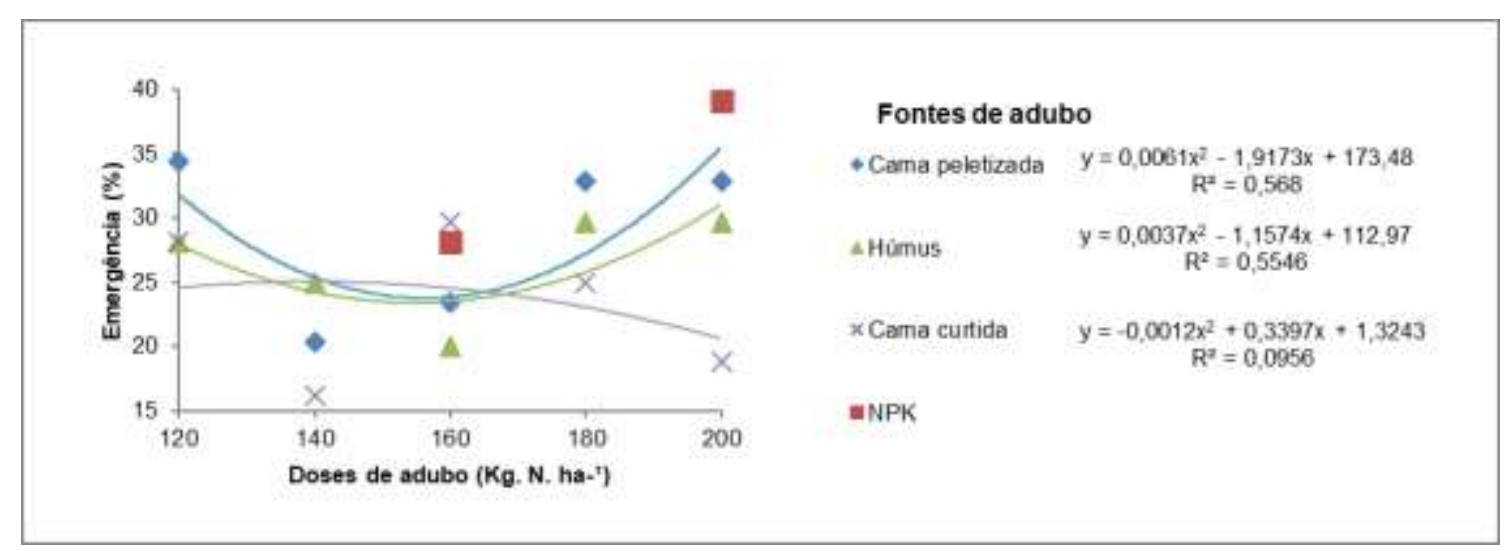

Fonte: Autores.

Para avaliação de patógenos identificou-se a presença de Pectobacterium sp, em $100 \%$ das plantas analisadas. $\mathrm{O}$ gênero das Pectobacterium sp. são bactérias responsáveis pela podridão-mole em tubérculos e/ou canela-preta em plantas de batata (Pérombelon \& Kelman, 1987, p.283; Duarte et al., 2004, p.532; El Tassa \& Duarte, 2006, p.25). Sintomas de podridão mole começam como uma pequena lesão de encharcamento, com rápido alargamento no diâmetro e na profundidade. A área afetada torna-se mole e murcha enquanto a superfície torna-se descolorida e um tanto quanto deprimida. Os tecidos nas regiões afetadas assumem coloração creme e levemente apodrecidos, desintegrando-se em uma massa podre com células desorganizadas da planta e das bactérias. Frutos ou tubérculos podem ser convertidos em uma massa aquosa, em um prazo de 3 a 5 dias (Carvalho Filho \& Mello, 2008). Os sintomas descritos correspondem com os verificados no experimento no momento da coleta das amostras.

Os resultados obtidos para identificação de patógenos podem estar relacionados com os fatores climáticos após o plantio e o tipo de solo do experimento. Durante o período de pesquisa ocorreu precipitação (452,7 mm) (Figura 01), e temperatura média $23^{\circ} \mathrm{C}$ condições ideais para desenvolvimento e proliferação de patógenos. E ainda, fatores atrelados às 
características do solo, sendo um solo argiloso (acima de 60\% argila), possuindo grande retenção de água.

Os fatores acima mencionados também podem ter influenciado a germinação e emergência. O processo germinativo se inicia com a absorção de água por embebição, porém, há necessidade de que a semente alcance um nível de hidratação que permita a reativação dos seus processos metabólicos para o estabelecimento das plântulas (Guedes et al. 2011, p.281). Em condições de excesso hídrico, como encharcamento do solo, interfere no metabolismo, reduzindo a atividade enzimática, gerando alterações bioquímicas com reflexos na mobilização de reservas. Em condições de estresse hídrico por alagamento ocorre o decréscimo na germinação de sementes (Neto, 2012, p.39).

O efeito negativo da hipoxia (ausência de oxigênio suficiente nos tecidos) sobre vias metabólicas de hidrólise de reservas na semente e mobilização para a plântula podemresultar em baixos percentuais de emergência (Neto, 2012, p.38). O estresse abiótico prejudica o crescimento do eixo embrionário, assim como as rotas fisiológicas e bioquímicas responsáveis por desencadear o processo germinativo das sementes, reduzindo assim a porcentagem de germinação nas plantas (Rocha, 2019, p.43).

Outro fator que pode ter influenciado nos resultados é a liberação dos nutrientes no solo. O NPK apresenta a maior taxa de solubilidade e pode ter ocorrido lixiviação dessa fonte, devido ao volume de precipitação no período do experimento. Sendo que dentre as fontes orgânicas a que apresentou maior taxa de emergência foi a cama de aviário peletizada, que possui liberação mais lenta quando comparada às demais fontes de adubação.

Os adubos orgânicos podem ter imobilização de nutrientes do solo no primeiro mês após sua incorporação. Depois desse período, a liberação aumenta progressivamente, atingindo as maiores quantidades entre três e seis meses após a incorporação (Cancellier et al.,2010, p.27), corroborando assim com os dados obtidos no presente trabalho.

Cancellier et al.,(2010, p.28) avaliando a emergência de plantas de milho (Zea mays), utilizando os adubos minerais, (NPK e uréia) e esterco bovino verificaram menor númerode plantas emergidas. Quando os autores empregaram as maiores doses de esterco, obtiveram maior número de plântulas emergidas na primeira avaliação. Os autores afirmam que pode ser explicado pelas melhores condições de estrutura e aeração do solo, como também, pelo fornecimento de nutrientes proporcionados pela matéria orgânica e melhor disponibilidade hídrica para a planta fornecida via esterco, ratificando o presenteestudo.

Resultados contrários aos verificados neste trabalho foram obtidos por Duarte et al. (2010, p.35) para a cultura da melancia (Citrullus lanatus (Thumb.) Matsum. \& Nakai). naregião de Manaus- AM. na produção de mudas em bandeja de poliestireno utilizando a cama de aviário como fonte de adubação no substrato. Os autores observaram que o índice de velocidade de emergência apresentou um comportamento linear crescente com as doses de cama de aviário, após a emergência, e observou-se um efeito danoso na maior dose (4 Litros) utilizada nas mudas. Devido a maior quantidade de adubos em contato com as plantas logo após a emergência devido ao espaço ser limitado e sua incorporaçãoser lenta.

Kawakami (2015, p.170) na região de Guarapuava-PR, durante o ano de 2006, utilizando-se a cultivar Ágata, com as adubações da dose usual 4 t ha-1 ${ }^{1}$ NPK (4-14-8), 75\% e $150 \%$ da dose. No estádio de florescimento (33-35 DAE), não observou diferençaestatística significativa em nenhum dos parâmetros analisados entre os tratamentos. No estádio de máximo crescimento vegetativo (47 e 58 DAE) não identificou diferença estatística entre os tratamentos, no número e MS de tubérculos. Após a maturação fisiológica, na colheita final, não constatou diferença significativa entre os tratamentos no período entre a emergência das plantas e maturação fisiológica (período de crescimento), no número e na porcentagem de MS de tubérculos. De acordo com o pesquisador estes fatos podem estar atrelados a aplicação única da dose antes do plantio, sendo que pode ter ocorrido lixiviação dos nutrientes fornecidos via solo.

Queiroz (2011, p. S2130), na safra da seca de 2010, entre os meses de agosto e dezembro, no município de Itajubá, Sul de Minas Gerais, utilizando doses crescentes de N (0,70, 140, 210 e 280 kg ไha-1 ${ }^{1}$. Verificou que em relação a 
produtividade total de N, não foi observada diferença estatística entre as doses estudadas. Com relação à classificação dos tubérculos em Tipo I, Tipo II, Tipo III, Tipo IV e descarte, verificou-se que houve diferença significativa apenas para o tipo I, em função das doses de $\mathrm{N}$ utilizadas. Segundo o autor, esse resultado pode estar relacionado a maior dose de $\mathrm{N}$, que proporcionou maiorárea foliar, podendo assim ter maior produção de fotoassimilados destinados aos tubérculos.

Em experimento realizado no município de São Joaquim - SC, durante o ciclo de cultivo 2009/2010 utilizando a cultivar Catucha com quatro doses de fosfato natural Gafsa (0,1333, 2666 e $\left.4000 \mathrm{~kg} \mathrm{ha}^{-1}\right)$, Nava (2017, p.90) observou que a produtividade total detubérculos foi sempre superior a $20 \mathrm{t} \mathrm{ha}^{-1}$ e não foi influenciada significativamente pelostratamentos. Nos tratamentos que haviam recebido fosfato natural, independentemente da dose, as produtividades foram similares ao tratamento que havia recebido somente a camade aviário. Portanto, sua utilização não trouxe benefícios quando combinado com a camade aviário. Conforme o autor, estes resultados podem estar relacionados à baixa respostado fosfato natural Gafsa é o ciclo relativamente curto da cultura da batata, não havendo tempo suficiente para que o fosfato natural pudesse ser solubilizado ao ponto de suprir a demanda das plantas por P. Além disso, espécies com o sistema radicular pouco desenvolvido, a exemplo da batata, podem apresentar baixa resposta ao uso de fosfato natural.

Quando observado a emergência e somente os custos para aquisição de cada fontee dose de adubação. A adubação com cama peletizada $120 \mathrm{~kg}_{\mathrm{N} \backslash h \mathrm{-}^{-1}}$ apresenta custo de R \$5.400,00 hha e 34,37\% de emergência, logo resulta em melhor custo benefício. Cama de aviário peletizada na dose $180 \mathrm{~kg} h \mathrm{ha}^{-1}$ proporcionou 32,81\% de emergência, porém seu custo é de $\mathrm{R}$ $\$ 8.100,00$ ไha, não sendo viável sua utilização nesta dosagem. Cama curtida $160 \mathrm{~kg} \backslash \mathrm{N} \backslash \mathrm{ha}^{-1}$ mesmo não apresentando os maiores percentuais de emergências pode ser uma opção de utilização, pois custou de R $\$ 4.800,00$ hha e $29,8 \%$ de emergência. As testemunhas, NPK $160 \mathrm{~kg} \backslash$ ha possui custo de R $\$ 8.480,00$ e $28,12 \%$ e a de $200 \mathrm{~kg} \mathrm{ha}{ }^{-1}$ custo de $\mathrm{R} \$ 10.600,00$ e $39,06 \%$, não sendo viáveis economicamente quando comparadas e cama peletizada $120 \mathrm{~kg} \backslash \mathrm{ha} \mathrm{-}^{-1}$.

O NPK $200 \mathrm{~kg} \backslash \mathrm{Nlha}^{-1}$ embora tenha apresentado valores superiores aos demais tratamentos não é usualmente utilizado pelos bataticultores.

\section{Conclusão}

Conclui-se que a fonte de adubo orgânico cama de aviário peletizadana dose $120 \mathrm{~kg}_{\mathrm{haa}}{ }^{-1}$ favorece a emergência de tubérculos de batata cv. Ágata, nas condições impostas pelo experimento.

\section{Agradecimentos}

Os autores agradecem pelo apoio oferecido através do Projeto PES-2019-0625 EDITAL No 459/GR/UFFS/2019 e Chamada MCTIC/MAPA/MEC/SEAD - Casa Civil/CNPq No 21/2016

\section{Referências}

Alfenas, A. C., \& Mafia, R.G. (2016) Métodos em Fitopatologia. (2a ed.), UFV. 516p.

Araujo, R. G. V. (2020) Desenvolvimento de tubérculos de rabanete em função de diferentes concentrações de húmus de minhoca. Ciência Agrícola. 18, p. $1-5$.

Armond, C. (2016) Desenvolvimento inicial de plantas de abobrinha italiana cultivada com húmus de minhoca. Horticultura Brasileira 34, 439-442 http://dx.doi.org/10.1590/S0102-05362016003022

Bisognin, D. A. (2009) Desenvolvimento e manejo das plantas para alta produtividade e qualidade da batata. Associação Brasileira da Batata.30p.

Braun, H., Fontes, P. C. R., Finger, F. L., Busato, C. \& Cecon, P. . (2010) Carboidratos e matéria seca de tubérculos de batata influenciados por doses de nitrogênio. Ciência e agrotecnologia. 34, 285-293.

Calviglione, J. H. (2000) Cartas climáticas do Paraná: edição ano. versão 1.0. IAPAR

Cancellier, L. P. (2010) Influência da adubação orgânica na linha de semeadura na emergência e produção forrageira de milho. Revista Verde. 5, 25 - 
32.

Cardoso, A. D., Alvarenga, M. A. R., Dutra, F. V., Melo, T. L. \& Viana, A. E. S. (2017) Características físico-químicas de batata em função de doses e fracionamentos de nitrogênio e potássio. Revista de Ciências Agrárias. 4 0 , p. 567-575.

Carvalho Filho, R. C. \& Mello, S. C. M. (2008). Pectobacterium carotovorum: taxonomia, identificação, sintomatologia, epidemiologia e controle. Documento 2061, Embrapa Recursos Genéticos e Biotecnologia.

Coelho, D. S., Simões, W. L., Mendes, A. M. S., Dantas, B. F., Rodrigues, J. A. S. \& de Souza, M. A. (2014) Germinação e crescimento inicial de variedades de sorgo forrageiro submetidas ao estresse salino. Revista Brasileira de Engenharia Agrícola e Ambiental. 18, p.25- 30.

Duarte, A. K. A., Cardoso, M. O. \& Figueiredo, L. (2010) Crescimento e macronutrientes em mudas de melancia com doses de adubo orgânico. Horticultura Brasileira, 28, p. 1633-1638.

Duarte,V., DE Boer, S. H., Ward, L. J. \& De Oliveira, A. M. R. (2004) Characterization of atypical Erwinia carotovora strains causing blackleg of potato in Brazil Journal of Applied Microbiology, 96, p.535-545.

El T. S. \& Duarte V. (2006) Identificação de Pectobacterium carotovorumsubsp. brasiliensis através de PCRRFLP do gene recA. Fitopatologia Brasileira 31, p.023-028.

Freitas, C. A., Silva, C. J., Silva, C. A., Castro, Y. de O. ; Rosa, A.J., \& Lourenço, M. F. de C. (2012) Desenvolvimento de mudas de cafeeiro (Coffea Arabica L.) emfunção de doses de húmus de mata no substrato comercial. http://www.sbicafe.ufv.br:80/handle/123456789/6107

Girotto, P. H., Rosa, G. G., Baranek, E. J., Kawakami, J., \& Lima, C. S. M. (2021) Adubação nitrogenada orgânica influencia na classificação comercial de batatas cv. Asterix. Research, Society and Development, 10, p.1-8. http://dx.doi.org/10.33448/rsd-v10i5.14595

Góes, G. B. (2011) Utilização de húmus de minhoca como substrato na produção de mudasde tamarindeiro. Revista Verde. 6, p.125 - 131.

Gonçalves, M. S. (2013). Caracterização de cama de frangos e perus visando o manejo adequado de resíduos avícolas, III Symposium on Agricultural and Agroindustrial WasteManagement.

Guedes, R. S., Alves, E. U., Aalindo, E. A., \& Barrozo, L. M. (2011) Estresse salino e temperaturas na germinação e vigor de sementes de Chorisia glaziovii O. Kuntze. Revista Brasileira de Sementes, v. 33, p. 279 - 288.

Katayama, R. S. Eficiência de coberturas termorefletoras e difusoras no desenvolvimento da alface da alface submetida a diferentes doses de cama de aviário. Revista Científica Rural. 33, p. 279 - 288.

Kawakami, J. (2015) Redução da adubação e doses e parcelamento de nitrogênio no crescimento e produtividade de batata. Horticultura Brasileira, v. 33 , p.168-173.

Marangoni, L. D. (2014). Influencia do teor de umidade na germinação de sementes de Parapiptadenia rigida (BENTH.) BRENAN, Nativa, 2, p.124-128.

Mottin, M. C., Richart, A., Seide, E. P., Alves, A. L. \& Sostisso, P. H. (2015) Interferência do manejo da cama de aviário na liberação de nitrogênio para o solo. Journal of Agronomic Sciences. 4, p.158-171.

Nava, G. (2017) Uso de fosfato natural Gafsa e cama de aviário em sistema orgânico deprodução de batata. Revista de Ciências Agroveterinárias, 16, p.8894.

Neto, A. G. (2012) Níveis de umidade do solo de várzea e seus efeitos sobre a emergênciae crescimento inicial de plântulas de soja, ABRATES, 22 , pp.35-42.

Nobile, F. O., Prado, R. M \& Spadoni, T. B. (2012) Adubação nitrogenada e critérios de amostragem foliar para acultura da batata. Comunicata Scientiae. 3 , p23-29.

Passos, S. Desempenho de cultivares de batata em sistema orgânico: crescimento, produtividade e resposta a requeima e a larva alfinete. 2016. Universidade Estadual do Centro-Oeste, UNICENTRO, Guarapuava, PR.

Peixoto Filho, J. U., Freire, N. B. G. S, Freire, F. J., Miranda, M. F. A., Pessoa, L. G. M., \& Kamimura, K. M. (2013). Produtividade de alface com doses de esterco de frango, bovino e ovino em cultivos sucessivos, Revista Brasileira de Engenharia Agrícola e Ambiental, 17, p.419-424.

Pereira, M. R. R. ( 2012) Influência do estresse hídrico e salino na germinação de Urochloa decumbens e Urochloa ruziziensis, Bioscience Journal, 28, p. 537-545.

Pérombelon, M. C. M. \& Kelman, A. (1987) Blackleg and other potato diseases caused by soft rot Erwinias: Proposal for revision of terminology. Plant Disease. 71, p.283-285.

Queiroz, A. A., Luz, J. M. Q., Souza, B. U., Souza, M. C. U, Mundim, F. M., Leite, S. S. \& Queiroz, A. A. (2011) Classificação de tubérculos de batata cultivar Ágata em função de doses de nitrogênio, Horticultur Barasileira. 29, S2129-S2135.

Queiroz, L. R. (2013) Adubação NPK e tamanho da batata-semente no crescimento, produtividade e rentabilidade de plantas de batata, Adubação NPK e tamanho da batata semente no crescimento, produtividade e rentabilidade de plantas de batata. HorticulturaBrasileira . 31, p.119-127.

Reis, F. S. M. (2018) Dosagens de Cama de Aviário Peletizada Aplicada Superficialmente no Cultivo de Alface. XII Reunião brasileira de ciência do solo.

Rocha, G. T., Rocha, G. T. \& Rocha, G. T. (2019). Efeito da salinidade na germinação de pepino. Revista Brasileirade Agropecuária Sustentável, 9, 41-46.

Sangoi, L. (2009) Desenvolvimento inicial do milho em função de doses e fontes denitrogênio aplicadas na semeadura, Revista Biotemas. 22, 53-58 
Research, Society and Development, v. 10, n. 7, e52910716107, 2021

(CC BY 4.0) | ISSN 2525-3409 | DOI: http://dx.doi.org/10.33448/rsd-v10i7.16107

Sausen, D. (2020). Biomassa de clones de batata submetidos a doses contrastantes defósforo no solo, Brazilian Journal of Developement. 6 , $7479-7487$.

Silva, G. O. \& Carvalho, A. D. F. (2015). Sistema de Produção da Batata. (2a ed.), Embrapa, p. 80-82.

da Silva Júnior, E. D., Maia, J. M., da Silva, A. F., Santos, E. E. S., Rech, E. G., de Almeida, R. A. (2015). Influência de composto orgânico na germinação e desenvolvimento inicial de melancia. 11, p.1983-4209.

Souza, M. F., Martins, E. R., Fernandes, L. A., Nere, P. S. (2016) Emergência e desenvolvimento inicial de sementes de Dimorphandra mollis Benth. em campo, Revista Brasileira de Plantas Medicinais. 18,p.186-190.

Weeks, D. P. (2017). Gene Editing in Polyploid Crops: Wheat, Camelina, Canola, Potato, Cotton, Peanut, Sugar Cane, and Citrus. (ed tec) Progress in Molecular Biology and Translational Science. 149, p.65-80. 